\title{
Successful treatment of huge pituitary macroadenoma secreting TSH and GH
}

Agnieszka Adamska, Agnieszka Zapora-Kurel, Maria Górska

Department of Endocrinology, Diabetology and Internal Medicine, Medical University of Białystok, Poland

\section{Introduction}

The mixed tumor which secretes an excess of both $\mathrm{GH}$ and TSH causing acromegaly and hyperthyroidism is rare. The main problem is the late diagnosis, especially in men, even 10 years after the occurrence of the first symptoms.

\section{Case presentation}

\section{Main complaints}

A 53-year-old men, was admitted to the our department in 13.01.2014, with complaints of excessive sweating, palpitation, headache, blurred vision and enlargement of the hand and feet.
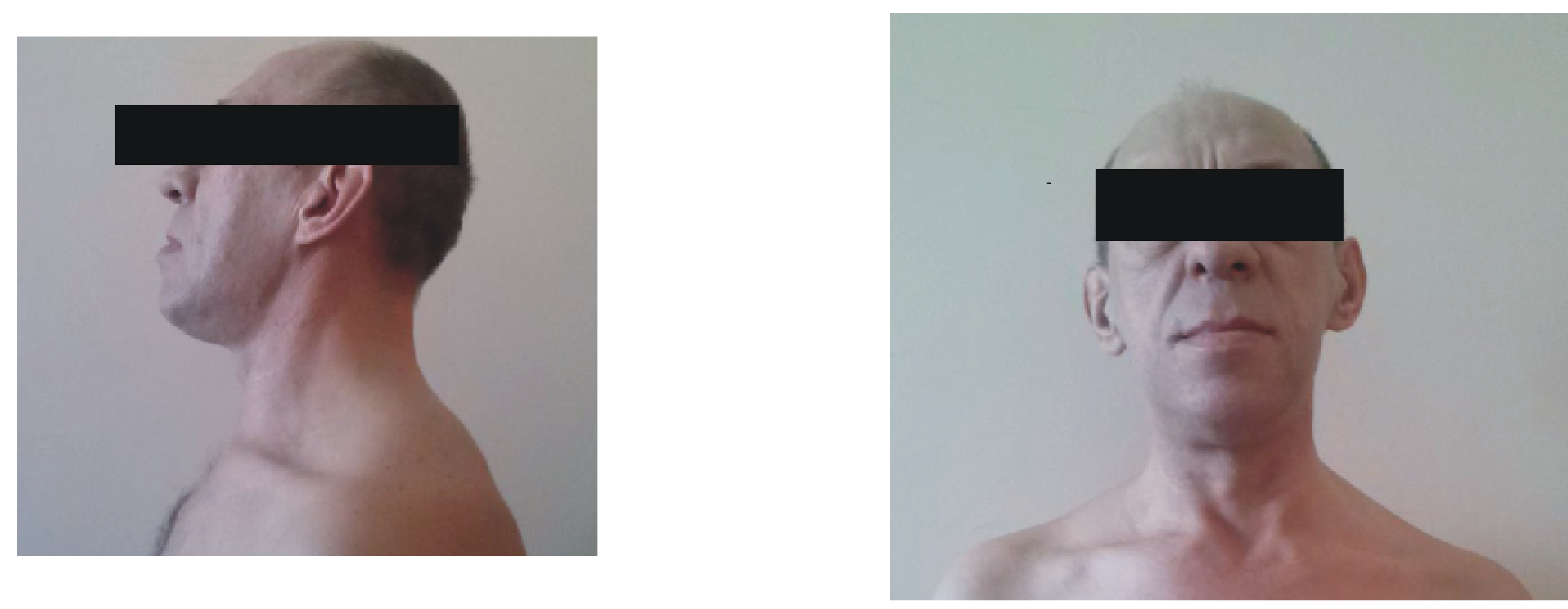

\section{History of presenting complains}

Patient has noticed symtoms for the first time two years ago.

\section{Past medical history}

Past medical history revealed subtotal thyreoidectomy 20 years ago.

\section{Review of systems}

His medical history included arterial hypertension.

\section{Physical examination}

Physical examination showed typical signs of acromegaly and nodules in both lobes of the thyroid gland.

\section{Investigation}

Initial laboratory testing revealed central hyperthyroidism (Table 1, 2) in addition to autonomic secretion of GH (Table 1).

\section{Table 1}

\begin{tabular}{|c|c|c|}
\hline Test & Value & Nomal range \\
\hline CH (basal) (ng/ml) & 7,2 & (1-5) \\
\hline $\begin{array}{l}\text { CH (after } 75 \mathrm{~g} \\
\text { glucose) }(\mathrm{ng} / \mathrm{ml})\end{array}$ & 6.67 & below 0.4 \\
\hline IGF-1 (ng/ml) & $\mid 593$ & |(87-267) \\
\hline TSH (mU/ml) & 6.095 & $(0.35-4.94)$ \\
\hline freet4 (ng/ml) & 3.09 & $(0.7-1.48)$ \\
\hline freeT3 (Pg/ml) & 17.49 & $(1.45-3.48)$ \\
\hline PRL (ng/ml) & 79.52 & $(0-29)$ \\
\hline
\end{tabular}

Table 2

\begin{tabular}{|l|l|}
\hline Test with TRH & Value \\
\hline TSH 0' & 3.6937 \\
\hline TSH 20' & 6.9201 \\
\hline TSH 60' & 6.0099 \\
\hline TSH 90' & 7.0608 \\
\hline TSH 120' & 5.1322 \\
\hline
\end{tabular}

\section{Other tests}

24-h urine collection for cortisol (norm rage to 176): $16.8 \mathrm{ug} / 24 \mathrm{~h}$

ACTH: $40.7 \mathrm{pg} / \mathrm{ml}$

Test with ACTH (250ug cosynotropin)- cortisol 0'- 5.7 ug/dl, 30'-14.9 ug/dl, 60 $18.3 \mathrm{ug} / \mathrm{dl}$

LH: $2.45 \mathrm{mlU} / \mathrm{ml}$, FSH:2.92 $\mathrm{mlU} / \mathrm{ml}$

Magnetic resonance imaging (MRI) of the sella revealed a large pituitary macroadenoma measuring $5 \times 6 \times 6 \mathrm{~cm}$ with left cavernous and sphenoid sinus invasion, with compression of the optic chiasm, the third ventricle as well as the brainstem.
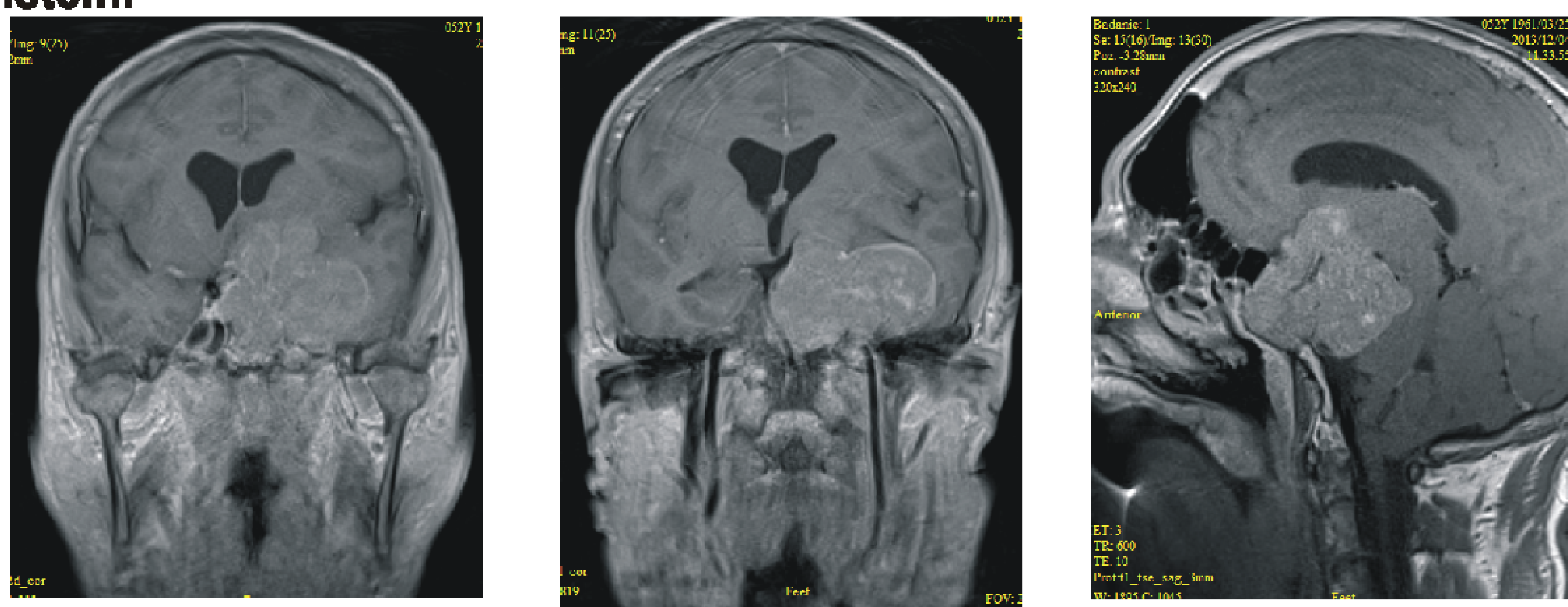

\section{Other investigation}

Vision field revealed bi-temporal hemianopia.

USG of the neck:
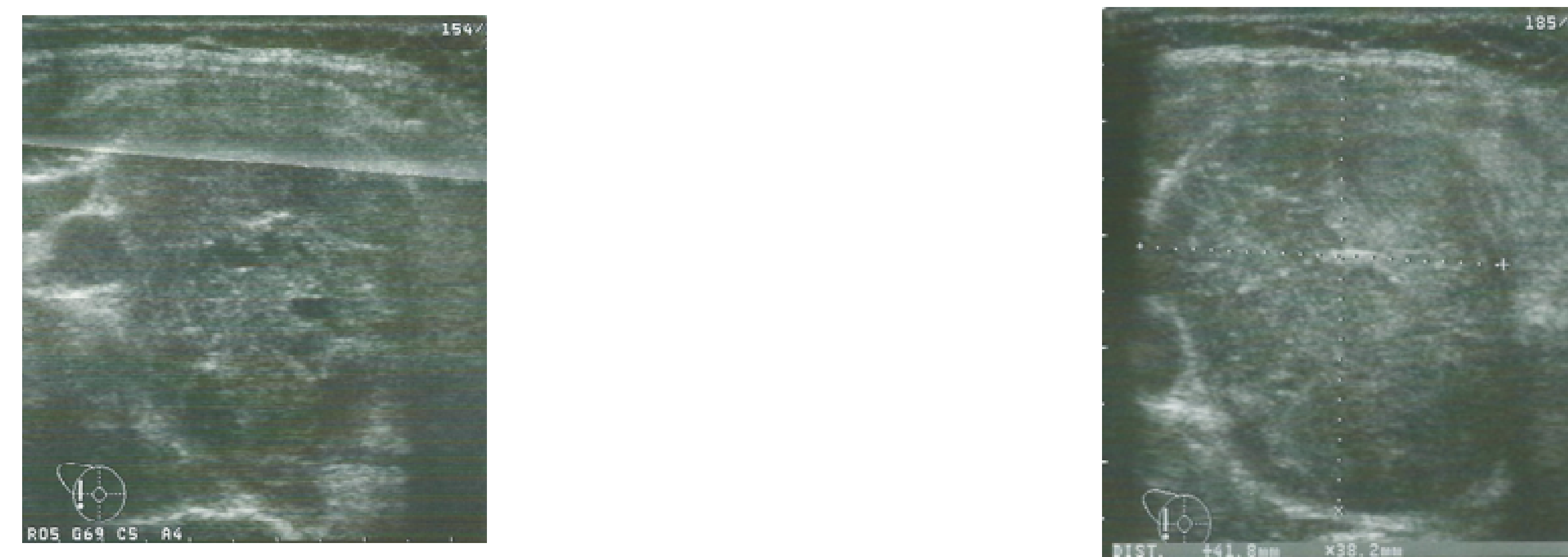

\section{Treatment}

1. Pre-operative treatment with thiamazole and octreotide LAR was initiated.

2. Patient proceeded to transsphenoidal resection of the pituitary macroadenoma (07.2014- first stage) with consecutive partial reduction of the tumor mass.

3. The left site temporal craniotomy (02.2015- second stage) with partial resection of the tumor has been performed. An improvement of vision and peripheral facial nerve paralysis on the left side was noticed after operation. After neurosurgery laboratory signs of hyperthyroidism resolved but serum $\mathrm{GH}$ concentration was still elevated. Currently, the patient is under octreotide LAR therapy.

\section{Conclusions}

We presented an unusual case with a huge pituitary macroadenoma secreting TSH and GH. Patient was successfully treated with transsphenoidal adenomectomy (at the first stage) and additional cranlotomy with the partlal resectlon of the tumor. Thls case showed that despite of symptoms and size of mixed tumor, diagnosis could be missed for the long time. On the other hand, the proper preparation for surgery, lets avoid the complications during the perioperative period. 